\title{
Market-Driven Trading Blocs in East Asia: Empirical Evidence from 1980 to 2000
}

\author{
Deng-Shing Huang \\ Institute of Economics, Academia Sinica
}

\begin{abstract}
In this paper we apply the gravity model to provide empirical evidence of market-driven trading blocs in East Asia for the period from 1980 to 2000. Special attention is paid on the role of mainland China's openness in shaping East Asia's trade pattern. Several trading blocs are empirically supported from the regression. (1) Firstly, there is significant evidence of a trading bloc within a Chinese circle, including Taiwan, Hong Kong, and mainland China. Although trade flows between Taiwan and mainland China were severely suppressed before 1987, the Chinese circle as a whole is highly integrated in terms of trade, indicating the important role Hong Kong plays as a trading agent in the Chinese circle. (2) The East Asian bloc appeared in the late 1980s and became more and more significant in the early 1990s. Although the bloc phenomenon in East Asia weakened right after the Asian crisis, it re-fostered again a few years later.
\end{abstract}

- JEL classification: F14, F15

- Keywords: Trading blocs, Gravity model, East Asian bloc, Chinese circle

\section{Introduction}

Despite the proliferating regional trade arrangement, mostly free trade agreements (FTA), in many other regions, East Asian were relatively inactive in signing FTA during this period. In fact, it was not until 2001 the first East Asian

\footnotetext{
*Corresponding address: Deng-Shing Huang, Institute of Economics, Academia Sinica, 128, Sec.2, Academia Rd., Nankang, Taipei 11528, Taiwan. Tel: 886-2-27822791 ext 204; Fax: 886-2-27853946, E-mail: dhuang@econ.sinica.edu.tw 
countries related FTA were signed between Singapore and New Zealand. ${ }^{1}$ Thus, it would be fairly suitable to say that East Asia is a "region without regionalism"2 by the end of the twenty century. However, lacking a formal FTA seems not causing any disturbance for the fast growing trade within East Asia. In stead, as will be shown later, the intra-regional export and import share have been dramatically increasing and significantly above the world average during this period. This phenomenon clearly signs the power of market force, that will penetrate any trade barrier formed politically or non-politically.

While the market force in shaping a factual trading bloc seems very straightforward from an economic point of view, it is seldom a focus of studies in the literature on regional integration. Piazolo (1997) is an exception, in which the market force for trade integration between Eastern and Western Europe has found its empirical supports. Similarly, to what extent and how does the market force play the role in shaping trading blocs in East Asia during his without-regionalism period is thus worth pursuing. Logically, in the period of without FTA, any trading bloc is fundamentally market-driven. From this aspect, this paper will aim at finding the factual trading blocs in East Asia of Taiwan, Hong Kong, mainland China, South Korea, and Japan during the period from 1980 to 2000. More specifically, we apply the gravity model to investigate whether trade flows among the East Asian economies go beyond the 'normal' level implied by their corresponding GDP level, GNP per capita, geographical distance, and contiguous factors. Studies using the gravity equation to analyze the globalization of trade or regionalism of trade abound in the literature. Frankel (1992) applies the model to test whether a Yen bloc was fostered by the large volume of trade related with Japan in East Asia and Pacific Rim countries. Similarly, other related empirical studies include Frankel and Wei (1995) and Frankel et al (1995, 1996). Eichengreen and Irwin (1995) apply the gravity equation to analyze the effect of trade blocs and currency blocs on trade flows during the period from 1928 up to World War II. Trade blocs that were formed during the Great Depression in the late 1920s did not fade away along with the formation of GATT. On the contrary, regional trade arrangements, like preferential trade arrangements, free trade areas, and customs union, seem to have become even more popular in the recent decades. ${ }^{3}$

\footnotetext{
${ }^{1}$ For the development of FTA in East Asia see Lee and Park (2005).

${ }^{2}$ See Capie (2004) p149.

${ }^{3}$ See Grant ea al (1993)
} 
The trade pattern in East Asia is quite distinct from other regions. As we will discuss below, Japan and the U.S. have been playing an important role in the pattern of trade for Asian Pacific countries since the early 1960s. However, the openness of mainland China's market in the early 1980s gave a considerable shock to the pattern, probably due to its huge market size which changed the direction of trade in East Asian countries, and/or its abundance of cheap labor that consistently attracts foreign capital. A brief overview on the trade flows in the last two or three decades gives us a rough impression that East Asia is to some extent an integrated production center that provides manufacturing goods to the U.S. or the 'western' market. The openness of mainland China in the early 1980s made this pattern even more significant. Another purpose of this paper is to apply the gravity model to search out empirical support for such a view if it does exist.

The rest of this paper is organized as below. Section 2 briefly discusses the trade pattern in the East Asian countries, especially the so-called triangular trade pattern. ${ }^{4}$ In addition, the economic relations among the Chinese circle, namely Taiwan, Hong Kong, and mainland China will be addressed. In section 3 the gravity model will be discussed, and data sources and adjustment will be described. Furthermore, the empirical strategy for exploring whether there is a bloc-phenomenon in the area's trade will be introduced. Section 4 reports the empirical results and section 5 concludes the paper.

\section{Trade Pattern in East Asia}

\section{A. Triangular Trade Pattern in EA}

Ever since World War II, the trade pattern in East Asia has been highly dominated by the United States and Japan. For the export side, the U.S. is the largest export market for the East Asian NICs including Taiwan, South Korea, Singapore, and Hong Kong. For the import side, the roles of the U.S. and Japan are reversed. Japan is the major source of imports for all the Asian countries. For geographical and/or some historical reasons, Taiwan, South Korea, and Japan are to some extent in a special contiguity, economically and culturally. Beginning in the late 1960s, to overcome increasing costs from a high wage rate, Japanese firms

${ }^{4}$ The triangular pattern of trade in East Asia refers to the phenomenon of importing parts and components from Japan to the other East Asian countries, which in turn export the final manufacturing goods to the U.S. 
especially those in labor-intensive manufacturing sectors or production stages relocated their production to Taiwan and South Korea and even to other South East Asian countries. The direct investment from Japanese firms to Taiwan and South Korea contributed more trade flows between them, leading to a verticallyintegrated production linkage between the economies. The other East Asian countries became the downstream producers of Japanese firms. As a result, Japan has been the major supplier of parts and components for manufacturing goods in other East Asian countries since the early 1960s. The trade relationship among the U.S., Japan, and other East Asian countries is thus usually called a 'triangular trade' pattern, unique to the Pacific Asian trade.

\section{B. Role of Mainland China's Openness in the Early 1980s}

An important event that may have changed Asian Pacific's triangular-trade pattern was the openness of mainland China to the world market in the early 1980s. With the advantage of lower wages than other East and South East Asian countries, the PRC became the most attractive new land for multinational firms, including not just those from the U.S. and Japan, but also from Taiwan and South Korea, once having been on the major receiving end of international capital. Consequently, the openness of mainland China's market not only enhances the trade relation among East Asian countries, but also dilutes to some extent the role of U.S. and Japan in the trade pattern of the area. Among the changes, the impact on the economic relationship among the Chinese circle, namely, Taiwan, Hong Kong, and mainland China is probably the most remarkable one.

In 1988 the PRC officially launched an announcement to attract investment from Taiwan. At the other side of the strait, Taiwan's government lifted its martial law in 1987 and during the same year loosened the control over capital outflows. In 1990 the rule of 'Indirect Investment and Technical Cooperation in Mainland China' became effective, and thus Taiwanese investment through Hong Kong or another $3^{\text {rd }}$ country into mainland China became legal. Cultural and ethical similarities across the Taiwan Strait facilitated the speed of economic integration among the three economies of Taiwan, Hong Kong, and mainland China. As a result, during the period of 1979 to 1992 , the accumulated FDI in mainland China mostly came from East Asia, accounting for $71.41 \%$, in which $9.27 \%$ was from Taiwan, $53.14 \%$ from Hong Kong, and 9.00\% from Japan, while only $10.8 \%$ was from the United States. ${ }^{5}$ In the late 1990s, roughly one decade after its openness, the PRC became Taiwan's largest FDI target, inducing a great volume of flows in mostly parts and 
components of manufacturing goods from Taiwan to mainland China. As a result, mainland China surpassed the U.S. and became Taiwan's largest export market in $2001 .^{6}$

Mainland China's FDI from Taiwan did not appear in the official record until 1987. One year later, FDI into the PRC from Taiwan already surpassed that from Japan and the Unites States. The trend of growing FDI in mainland China from its neighbor countries has prevailed not only in the $1990 \mathrm{~s}$, but also into the $21^{\mathrm{st}}$ century. As a result, mainland China became one of the world's major producers for many labor-intensive products in the early 1990s and even for information technology (IT) products in the late 1990s. For example, in 2002 mainland China became the $3^{\text {rd }}$ largest supplier of IT products, of which $70 \%$ can be attributed to FDI by Taiwanese firms. This pattern of vertically-integrated production across the Taiwan Strait in the IT industry has induced an intensive relationship in the phase of commodity trade.

The joining of mainland China into the East Asian production linkage may have changed the relative position of the U.S. in the export markets for some individual countries, like Taiwan. However, for the East Asia economy as a whole, the U.S. is still the largest export market. In fact, there has been a huge trade-deficit in the U.S. against mainland China after the late 1990s, and the huge deficit is still on a rising trend. That is, the joining of mainland China into the world trade system seems to have enlarged the production system in East Asia. As a result, the joining of the PRC into the production system has not reduced the trade surplus of East Asia as a whole. We will turn to this point in the following section.

\section{Trade Share of the East Asia}

East Asia's share of the world's total exports and imports has risen steadily over the last two decades. A higher export share than import share over the years indicates a long-lasting trade surplus for East Asia, disregarding the openness of mainland China in the early1980s. Indeed, the trade surplus was expanding in the late 1980s and early 1990s.

Figure 1 plots four series of trade shares for East Asia, which are defined below: World export (import) share is the ratio of East Asian's total exports (imports) to

${ }^{5}$ See The Year Books of Statistics on Foreign Investment and Trade, People's Republic of China, various years.

${ }^{6}$ Related statistics are from Taiwan Statistical Data Book (various years), published by the Council for Economic Planning and Development, Taiwan, R.O.C. 
Figure 1. East Asia's Trade Share

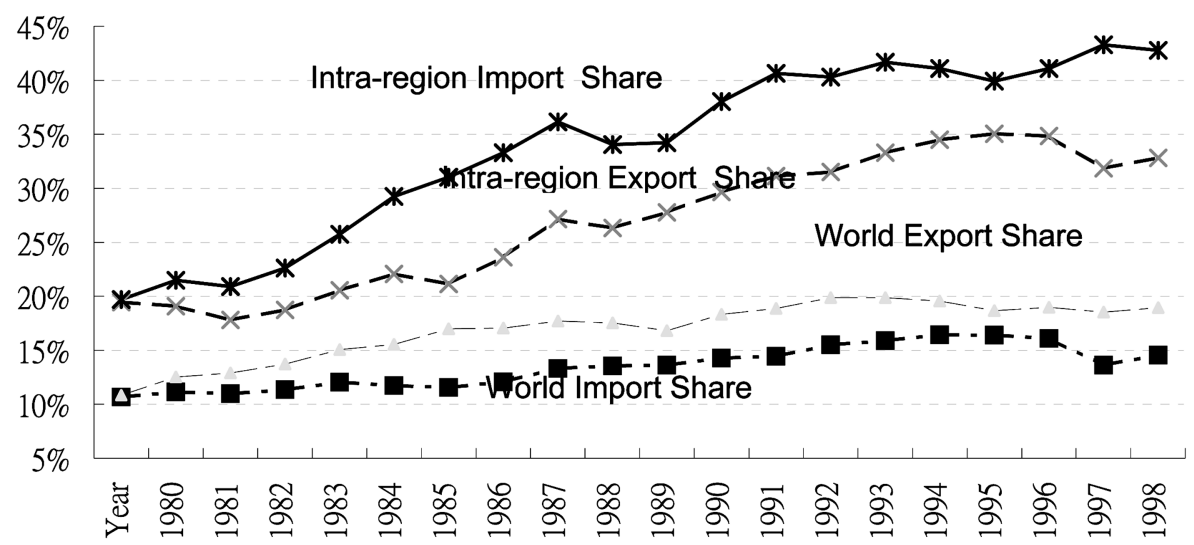

the world's total exports (imports). Intra-regional export share is defined as the ratio of intra-regional exports to the region's total exports. The same definition applies to the intra-regional import share. To be precise, let $X_{i j}$ denote total exports from country $i$ to $j$. Thus,

$X . . \equiv \sum_{i} \sum_{j} X_{i j}$ equals the world's total exports, which is equivalent to the world's total imports;

$X_{R} . \equiv \sum_{i \in R} \sum_{j j} X_{i j}$ equals the total exports of region $R$;

$X_{\bullet R} \equiv \sum_{i} \sum_{j \in R} X_{i j}$ equals the total imports of region $R$ and

$X_{R . R} \equiv \sum_{j \in R} \sum_{j \in R} X_{i j}$ equals region $R$ 's intra-regional exports, which by definition equals intra-regional imports.

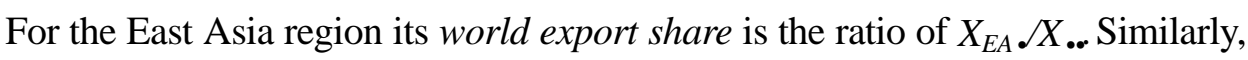
East Asia's world import share is $X_{E A} / X$...The intra-regional export share for East Asian countries is computed as $X_{E A . E A} / X_{E A \text {. }}$, and the intra-regional import share is $X_{E A . E A} / X \cdot E A$.

As we can see from the figure, for the five East Asian countries their world export share exceeds $15 \%$ in 1984 and kept rising to a peak of $20 \%$ in the early 1990s. Their world import share, although always smaller than the export share, has been rising over the same period and passed the level of $15 \%$ in 1992. Although the Asian Crisis in 1997 made the import share decline, the ratio rebounded quickly the next year. All in all, East Asia (EA) has been a trade surplus area in the world since the 1980s. The trade status has not changed despite the 
joining of mainland China with its huge domestic market.

The EA region on the other hand seems to be more vertically integrated in terms of the production chain. As shown in the figure, the intra-region import share is far greater than the intra-region export share in the last two decades. After 1991, more than $40 \%$ of EA's imports have been intra-regional, much higher than the share of intra-regional exports, which did not reach their peak of 35\% until 1996. The fact of a higher intra-regional import share versus export share reflects the vertical relationship in the production process for the EA.

Another facet worth noting is that for the East Asian economies, not only is the share of intra-regional exports greater than their share of the world's total exports, but also the share of intra-regional imports is greater than their share of the world's total import value. This phenomenon intuitively reflects the existence of a 'trading bloc' for the EA as a whole. As noted earlier, we will apply the gravity model to conduct an empirical test, to which we now turn.

\section{The Gravity Model}

\section{A. Basic Model}

Starting from Tinbergen (1962) and Linneman (1966), the gravity model has been shown to be empirically successful in explaining bilateral trade flows. ${ }^{7}$ The theoretical foundation of the gravity model can be found in Anderson (1979), Bergstrand (1985), and Feenstra et al (2001). The traditional gravity equation usually takes the following log-linear form: ${ }^{8}$

$$
\begin{aligned}
\log \left(V O T_{i j}\right) & =\alpha+\beta_{1} \log \left(G O P_{i} \cdot G D P\right)+\beta_{2} \log \left(G N P P C_{i} \cdot G N P P C_{j}\right) \\
& +\beta_{3} \log \left(D I S T_{i j}\right)+\sum_{k} \delta_{k} C N T G_{i j}^{k}+\sum_{r} \eta_{r} R G N_{i j}^{r}+u_{i j}
\end{aligned}
$$

where $V O T_{i j}$ denotes the volume of trade between country $i$ and $j$ (i.e., $\left.V O T_{i j}=X_{i j}+X_{j i}\right) ; G D P_{i}$ is the gross national product of country $i$; GNPPC $i$ is the GNP per capita of $i$; and $D I S T_{i j}$ is the transport distance between $i$ and $j$. In addition, $C N T G_{i j}^{k}$ is a contiguity dummy, which is defined as follows: If both country $i$ and $j$ are of the $k$ cluster (for example, common language, border, or cultural background), then $C N T G_{i j}^{k}=1$, otherwise $C N T G_{i j}^{k}=0$. The term $R G N_{i j}^{r}$ is a region dummy, which is defined as $R G N_{i j}^{r}=1$, if both $i$ and $j$ belong to

${ }^{7}$ See Deardorff (1984) for a survey.

${ }^{8}$ See Frankel (1992), Feenstra et al. (2001), and references therein. 
the same particular region of $r$, e.g., members of the same regional trade arrangement, free trade area, common market etc; otherwise, $R G N_{i j}^{r}=0$. Obviously, $u_{i j}$ denotes an error term.

Except for the region dummy, the other three groups of factors determine the basic gravity model. That is, bilateral trade flows between countries are in principle determined by the following three kinds of factors: (1) gross domestic products and GNP per capita, (2) transport distance, and (3) contiguity factors. Among the three, the first category denotes economic variables. They reflect the trade needs arising from economic incentives, as discussed in the conventional trade theory. Normally, a greater GDP and national income would induce a larger demand for foreign goods and thus lead to more trade flows between the countries. That is, theoretically we would expect a positive relationship between volume of trade and the two variables of $\log \left(G D P_{i} . G D P_{j}\right)$ and $\log \left(G N P P C_{i}\right.$. $\left.G N P P C_{j}\right)$, i.e., $\beta_{1}>0$, $\beta_{2}>0$. Intuitively, a positive coefficient of $\log \left(G D P_{i}\right.$. $\left.G D P_{j}\right)$, to be rewritten as $L G D P_{i j}$ hereafter, ${ }^{9}$ also indicates a positive relationship between market size and volume of trade. In the extreme case, either $G D P_{i}$ or $G D P_{j}$ approaching zero will result in no trade in between. A positive coefficient of the variable $\log \left(G N P P C_{i} . G N P P C_{j}\right)$, rewritten as $L G N P P C_{i j}$, also reflects a positive marginal import propensity as indicated by the trade theory. It also represents the income similarity argument in the new-trade theory of the 1980s. That is, the higher the degree is of income similarity between countries, the greater the intra-industry trade will be. ${ }^{10}$

In addition to the conventional gravity factors, we may also consider another economic factor of the real effective exchange rate. Theoretically, the real depreciation of a country's currency should lower the relative price of its exportables in the world market and thus facilitate its export to its trade partners. On the other hand, the import goods become more expensive and thus will be imported less than before. As a result, for each pair of countries, $i$ and $j$, the bilateral trade volume can be affected by the real exchange rate in either direction, depending on the magnitude of export elasticity and import elasticity. As a proxy for the real effective exchange rate, we adopt the purchasing power parity ${ }^{11}$ in the regression, simply due to the limited availability of the real effective change rate.

\footnotetext{
${ }^{9}$ Similarly, $\log \left(V O T_{i j}\right)$ will be rewritten as $L V O T_{i j}$ hereafter.

${ }^{10}$ This is also called Linder's Hypothesis. According to the related literature, the causes of intra-industry trade include economies of scale, heterogeneity of commodity, income similarity and multinational firms, and the degree of economic developments. See Chow et al (1999) for a discussion. See also Feenstra et al (2001).
} 
More specifically, $\log \left(P P P_{i} . P P P_{j}\right)$ (to be denoted as $L P P P_{i j}$ later on) will be included in the regression. By this setting we explicitly assume that the effects of real appreciation in either of the countries on the corresponding volume of trade are equal in magnitude.

The transport distance is a natural barrier of trade as a longer distance represents more transaction costs required. Thus, we expect a negative impact of $\log \left(D I S T_{i j}\right)$ on bilateral volume of trade, i.e., $\beta_{3}<0$. The contiguity variable, $C N T G_{k}$, captures the effect of other indirect transaction costs. For example, trade partners sharing a common cultural background or same language tend to have lower transaction costs, which in turn will lead to more trade flows in between. Thus, in this case the estimated coefficient is expected to be positive. ${ }^{12}$ On the contrary, for those common features that disturb any trade possibility, we would expect a negative coefficient. In this paper we consider two kinds of contiguity dummy; that is, $A D J_{i j}$ for a common border and ComLng $g_{i j}$ for a common language. As discussed before, we would expect their coefficient to be positive.

The region dummy $R G N_{i j}^{k}$ captures other factors, to be designed later to suit our purpose of seeking evidence of a trading bloc. For example, the harsh political relationship across the Taiwan Strait has enlarged the trading cost between Taiwan and mainland China. Thus, one would expect a below average level of trade flows between them. On the contrary, a preferential trade arrangement such as a free trade area, common markets, or customs union tend to enhance volume of trade among member countries. Following Frankel and Wei (1995), we can also design the 'openness' dummy for an economy or a region to investigate its degree of openness toward the world market. We will come back to this point later on.

To summarize, the gravity equation can be rewritten as follows: $:^{13}$

$$
\begin{aligned}
L V O T_{i j} & =\alpha+\beta_{1} L G D P_{i j}+\beta_{2} L G N P P C_{i j}+\beta_{3} L D I S T_{i j}+\delta_{1} A D J_{i j} \\
& +\delta_{2} \text { ComLng }_{i j}+\gamma . L P P P_{i j}+\sum_{r} \eta_{r} R G N_{i j}^{r}+u_{i j}
\end{aligned}
$$

\footnotetext{
${ }^{11}$ The purchasing power parity conversion factor, retrieved from the WDI database, is defined as "the number of units of a country's currency required to buy the same amount of goods and services in the domestic market as a U.S. dollar would buy in the United States."

${ }^{12}$ From Rauch (1999)'s gravity equation estimation, trade flows attributed from a common language and colonial relationship are greater than those induced by product differences. Applying the same approach on the trade blocs in the 1930s, Eichengreen and Irwin $(1995,1996)$ also find empirical support for the effects of historical and colonial relationships on trade flows.

${ }^{13} \mathrm{~A}$ list of variables and its definitions in the regressions are reported in Appendix 1.
} 


\section{B. Data and Dummy Variables}

This section discusses data sources and the adjustment required. In addition, the empirical strategy will be introduced, especially how a region dummy is designed to test the existence of a regional trading bloc.

To estimate the gravity equation we need basic data such as bilateral trade flows, GDP, GNP per capita, and the transport distance between countries. Panel data covering the years of 1980, 1985, 1990, 1995, 1998, and 2000 are constructed, simply due to the consideration of the two critical years 1987 and 1997. The year 1987 was a turning point for East Asia, especially for the Chinese area, when Taiwan's government officially lifted martial law, deregulated capital controls, and allowed more economic activities with mainland China. At the same time, mainland China's open policies began to be effective. The year 1997 refers to the Asian Crisis. Data for this year may not be normal and some structural change may occur after this event.

During the regression, year-specific dummies are considered. For example, Yr1985 refers to the observation for year 1985, which takes a value one if the observation belongs to 1985, otherwise zero. Clearly, $\operatorname{Yr} 1990$ refers to observation of 1990, not to mention $\operatorname{Yr} 1995, \mathrm{Yr} 1998$, and $\mathrm{Yr} 2000$.

\section{(1) Trade Data}

The trade flows are extracted from the World Trade Database of Statistics Canada, which is derived from United Nations COMTRADE data. Two adjustments about the trade flows' data can be made before proceeding to the regression analysis. Firstly, for the case when bilateral trade is zero, the dependent variable $\log \left(V O T_{i j}\right)$ is replaced with $\log \left(V O T_{i j}+1\right)$; that is, the volume of trade is assigned a value of one, which is the same approach as adopted in Eichengreen and Irwin (1995). ${ }^{14}$

Secondly, we acknowledge the existence of indirect trade between Taiwan and mainland China by re-exporting through Hong Kong customs, especially during the period before 1987 when economic interaction across the Strait was officially prohibited. In other words, the trade flows across the Taiwan Strait are underestimated to some extent, ${ }^{15}$ while the trade volume between Hong Kong and

\footnotetext{
${ }^{14}$ Omitting the zero observation in the dependent variable leads to a selection bias problem. Instead of using the Eichengreen and Irwin (1995) approach as we have adopted, one may use the Tobit model to do the regression so as to remedy the censored problem of the dependent variable.
} 
mainland China are overestimated. To rectify this statistic bias, we have use estimated figures of indirect imports and exports between Taiwan and mainland China by re-exporting through Hong Kong, which is conducted by the Ministry of Economics, Taiwan, based on the statistics of the Customs of Taiwan and Hong Kong. ${ }^{16}$ More specifically, the trade flows between Taiwan and mainland China have been adjusted up by the amount of the estimated figures, and correspondingly the trade flows between Hong Kong and mainland China has been adjusted down by the same figures.

(2) Macro Data and Other Explanatory Variables

Macro economic variables GDP and GNP per capita are retrieved from the World Development Indicators, published by the World Bank. Taiwan's macro data are retrieved from Taiwan Statistical Data Book, published by the Council for Economic Planning and Development (CEPD), Taiwan, ROC. To be noted, the annual GDP figures are deflated to 1995 U.S. dollars. The GNP per capita has been transformed into international dollars by the purchasing power conversion factors.

Based on the availability of the macro economic variables, there are 108 countries in the sample for each year, except 1990, in which Kuwait is not included as no macro data is available, probably due to Persian Gulf War. ${ }^{17}$ In other words, there are only 107 countries included in the sample of 1990. Consequently, there are 5778 observations of bilateral volume of trade (that is, 108 times 107 and divided by 2) for each year of 1980, 1985, 1995, 1998, and 2000, and 5671 observations (that is, 107 times 106 and divided by 2) for year 1990. Thus, the pooled sample has observations of 34561 .

The transport distance is basically the sum of sea and inland routes. For the sea route, the distance between major ports is calculated. ${ }^{18}$ However, if more than one port is the case, then the average distance of all the navigation routes is adopted.

\footnotetext{
${ }^{15}$ In fact, the trade flows between Taiwan and mainland China for the years before 1987 have been recorded as zero in the World Trade Database.

${ }^{16}$ The estimated figures of indirect trade among the three economies are available in the Taiwan Statistical Data Book, Council for Economic Planning and Development (CEPD), Taiwan.

${ }^{17}$ See appendix 2 for the list of countries.

${ }^{18}$ The distances of sea routes are computed according to the "Distance Between Ports" (1976) published by the Defense Mapping Agency, Hydrographic Center.
} 
The inland transport distance is measured between the ports and the capital, and an average distance is taken if necessary. As a complement to the distance factor, a border dummy $A D J$ (the subscript $i j$ will be suppressed occasionally for simplicity) is also included in the regression. As discussed before, we would expect a negative coefficient for the log of the distance variable, LDIST, and a positive coefficient for the adjacent variable, $A D J$.

(3) Regional Dummy

To suit our goal, two types of region dummies are designed; one is a type of simple regional dummy and the other is a year-specific regional dummy. For example, to investigate the trading bloc of the so-called Chinese circle, two regional dummies of the first type are designed, $C n T$ and $C H T$. The dummy $C n T$ refers to mainland China and Taiwan, and takes a value one if the observation is about trade between Taiwan and mainland China (i.e., if both countries $i$ and $j$ represents Taiwan or mainland China); otherwise zero. Similarly, the CHT refers to the region group of mainland China, Hong Kong, and Taiwan. Theoretically, a positive coefficient of a region dummy, say $C H T$, implies there are above normal trade flows within the region during the period studied, ranging from 1980 to 2000 .

The bloc phenomenon of a region may have changed over the period. Thus, the year-specific region dummy is constructed to examine whether and when a change has occurred. For example, to investigate whether there is a structural change in the degree of trade intensity between Taiwan and mainland China before and after 1987, the year-specific $C n T$ is constructed. More specifically, the year-specific dummy CnT_1980 (constructed by CnT times $\operatorname{Yr1980}$ ) has a value one if the observation is for 1980 and about the bilateral trade between mainland China and Taiwan. T he same system applies to $C n T \_1985, C n T \_1990$ etc. In some cases, we also include the multi-year specific dummy $C n T_{-} P 1990$ to represent $C n T$ and the years of and after 1990. That is, CnT_P1990 $=C n T^{*}(\operatorname{Yr} 1990+\operatorname{Yr} 1995+\operatorname{Yr} 1998+$ $Y r 2000)$. Theoretically, we would expect a significantly negative coefficient for CnT_1980 and CnT_1985, or a 'relatively' positive coefficient for CnT_P1990, if the harsh relationship between Taiwan and mainland China made trade flows across the Strait below their normal level especially in the early 1980s. For the region dummy CHT, the year-specific dummies of CHT_1980, CHT_1985, etc. are also constructed for the purpose of testing whether there is a Chinese circle and for how long it has been existed.

The dummy variable EA5 refers to the five East Asian economies of mainland 
China, Hong Kong, Taiwan, South Korea, and Japan. As a complement, we also include the regional trade arrangements of ASEAN, NAFTA, and EU. For ASEAN (Association of South East Asian Nations), only five of the member countries are included, because of data availability; they are Singapore, Thailand, Malaysia, Indonesia, and the Philippines. According to the development of the North American Free Trade Area, the regional dummy NAFTA includes two member countries of the United States and Canada before 1994, and one more member of Mexico in the year of and after 1995. Similarly, for the regional dummy representing EU, the region's members are adjusted along with their membership development. ${ }^{19}$ Following Frankel and Wei (1995), we can also design the 'openness' dummy for an economy or a region in order to investigate its degree of openness toward the world market.

\section{Empirical Results}

In this section several experiments will be conducted to seek empirical evidences of East Asian trade blocs if they do exist. Firstly, we begin searching for a benchmark model, in which the region dummies, especially $\mathrm{CnT}$ and $\mathrm{CHT}$ are considered directly. In section 4.2 the openness dummy will be designed and accompanied with a year-specific region dummy to investigate the empirical evidence of mainland China's openness beginning in the early 1980s. Section 4.3 examines the so-called Chinese circle. For this purpose, different combinations of year-specific $C n T$ and $C H T$ are considered in the regression to identify the development of a plausible trading bloc. Finally, section 4.4 focuses on investigating the evidence of a trading bloc for the East Asian five as a whole

\section{A. The Benchmark Model}

To search for a base model, we include the major gravity variables of GDP, GNPPC, distance, adjacency, and common-language dummy, etc., with different combinations of regional dummies, such as $C n T, C H T$, and EA5, and ASEAN, $N A F T A$, and $E U$. The log of real exchange rates crossed with various yeardummies are also included in the regression. All the models use the pooled sample, and the year dummies of Yr1985, Yr1990, Yr1995, Yr1998, and Yr2000 are

\footnotetext{
${ }^{19}$ For year 1980, the EU members were Belgium, Denmark, France, Germany, Ireland, Italy, Luxembourg, Netherlands, and United Kingdom. In 1981 Greece joined the group; in 1986 two more members (Portugal and Spain) entered; in 1995 Austria, Finland, Sweden became three new members.
} 
included in every model. Four of the major results using the OLS regression are reported in Table 1. Models 1 and 4 in the table are selected for a later experiment based on the criteria: (i) better goodness of fit and (ii) having a theoretically consistent sign of the estimated coefficient for the gravity variables (i.e., positive for $L G D P, L G N P P C$, and $A D J$, and negative for $L D I S T$.) Note that the LPPPrelated dummies selected into the model are confined to three years (LPPP_1980, LPPP_1985, and LPPP_1990), simply because other combinations of the LPPPrelated variables would violate the criteria (ii).

It may be worth noting here that from this very first experiment, we find a significantly negative coefficient (less than -6.7 in all the models) for the region dummy $C n T$. This result indicates to some extent that bilateral trade across the Strait is far below the normal level implied by their corresponding economic conditions and the geographical relationship. However, the estimated coefficient of

Table 1. Gravity Equation (Benchmark Model)

Dep. Variable: Log of Bilateral VOT

\begin{tabular}{|c|c|c|c|c|c|}
\hline Model & 1 & ? & 2 & 3 & 4 \\
\hline$\overline{\text { Indep. Vars. }}$ & Coeff. (Std. Err.) & Coeff. & (Std. Err.) & Coeff. (Std. Err.) & Coeff. (Std. Err.) \\
\hline Yr1985 & $-1.82545(0.1445)$ & -1.47872 & $(0.07783)$ & $-1.82753(0.1445)$ & $-1.82513(0.1$ \\
\hline r1990 & $-1.81406(0.1$ & -1.1776 & 34) & $19(0$. & -1. \\
\hline Yr1995 & $-2.98055(0.09659)$ & -0.63816 & $(0.0$ & $309(0$. & $-2.9758(0$ \\
\hline Yr1998 & $-2.76528(0.09675)$ & -0.42848 & $(0.0$ & $-2.76794(0.0$ & $-2.76066(0$ \\
\hline Yr2000 & $-2.81014(0.09721)$ & -0.48361 & $(0.08108)$ & $-2.81264(0.09723)$ & $-2.80561(0.09716)$ \\
\hline GDPij & $0.37494(0.00684)$ & 0.3011 & $(0.00695)$ & $0.37525(0.00685)$ & $0.37289(0.00685)$ \\
\hline GNPPCij & $0.10092(0.01816)$ & 0.23236 & $(0.0$ & 0.09955 & 0.10323 \\
\hline DIST & $-1.15304(0.01502)$ & -1.27913 & $(0.0$ & $291(0$. & $718(0$. \\
\hline ADJ & $0.5077 \quad(0.16131)$ & $0.24428^{\mathrm{a}}$ & $(0.16736)$ & $0.4772 \quad(0.16296)$ & $0.52622(0$ \\
\hline ComLng & & & & $0.09225^{\mathrm{a}}(0.0$ & \\
\hline PPP_1980 & 3.1 & & & $806(0.1$ & 8 \\
\hline PPP_1985 & $1.50044(0.07806)$ & & & 1.50162 & 1.49668 \\
\hline LPP_1990 & $1.40106(0.06514)$ & & & $1.40432(0.06518)$ & 1.39821 \\
\hline $\mathrm{CnT}$ & $-6.73554(2.02102)$ & -6.90221 & $(2.0$ & $-6.75263(2.02104)$ & $-6.7156(2.01979)$ \\
\hline CHT & $5.48513(1.16855)$ & 5.83216 & $(1.21303)$ & $5.41796(1.16965)$ & $1.38984^{\mathrm{a}}(1.32336)$ \\
\hline EA5 & & & & & $4.10883(0.62451)$ \\
\hline ASEAN & $4.24054(0.52459)$ & 3.83373 & 45) & $4.25013(0.52463)$ & $4.2571 \quad(0.52427)$ \\
\hline NAFTA & 5.79067 (1.1718) & 6.55012 & 33) & $5.77778(1.17183)$ & $5.79993(1.17109)$ \\
\hline$E U$ & $2.90424(0.23993)$ & 3.44653 & $(0.24877)$ & $2.9158 \quad(0.24009)$ & $2.92504(0.23981)$ \\
\hline Observations & 34561 & 34561 & & 34561 & 34561 \\
\hline Adj. $\mathrm{R}^{2}$ & .7728 & .7551 & & .7728 & .7731 \\
\hline
\end{tabular}

Note: All numbers without superscript 'a' are significant at $5 \%$ or $10 \%$ level. 
the Chinese circle dummy, $C H T$, appears to be significantly positive in the $1^{\text {st }}$ model. The contrasting result of a negative $C n T$ and a positive $C H T$ provides empirical evidence for the role of Hong Kong in facilitating indirect trade between mainland China and Taiwan.

Another interesting result arises in the $4^{\text {th }}$ model in which one more regional dummy of $E A 5$ is included in the explanatory variables. It shows that the region dummy of EA5 is significantly positive, while $C H T$ (although still positive) becomes insignificant. This evidence may imply that the trading bloc in East Asia, if it does exist in the last two decades, is a bloc of the five economies rather than of the three Chinese economies. We will dig into this phenomenon in more detail in the following experiments in section 4.4.

\section{B. The Openness of Mainland China}

We now turn to the effectiveness of mainland China's open-door policy beginning in the early 1980s. More specifically, we would like to see whether mainland China's trade to the rest of the world has gone back to normal and even beyond the level as implied by the basic gravity variables. For this purpose, an openness dummy $\mathrm{CHN}$, following the approach adopted by Frankel and Wei (1995), is constructed. That is, $C H N$ refers to mainland China-related trade with the rest of the world. In other words, the dummy $C H N$ equals one, if either the export side or the import side is the PRC, otherwise zero. In addition, the year-specific dummies for $C H N$, including $C H N \_1980, C H N \_1985, C H N \_1990$, etc. are also designed as explained before. For example, $C H N_{-} 1980=C H N *(Y r 1980)$. Theoretically, a higher coefficient of $C H N$ implies more openness by mainland China to the rest of the world. On the contrary, a negative coefficient represents that mainland China's trade is below 'normal', implying the ineffectiveness of its open policy in terms of trade.

Extending from the previous benchmark model (Model 1, Table 1), different combinations of $C H N$ and year-specific $C H N$ dummies are included in the regression, as reported in Table 2. Major findings regarding mainland China's trade from this table can be summarized as below:

(1) Mainland China's trade with the rest of the world during the last two decades is beyond the average level, as indicated by the positive coefficient of the $C H N$ dummy in all the three models. (Note: For model 1, the coefficient of 3.2944 applies to every sample year. For model 2 or 3, the estimated coefficient to a specific year, say 1980, should be the sum of coefficients for $C H N$ plus the 
coefficient for the corresponding year-specific dummy, CHN_1980.)

(2) The degree of openness varies over the years. For the years 1980 and 1985 the degree of openness for mainland China's trade is relatively lower than years after the 1990s. This is indicated by model 2 and model 3 in Table 2. It can be easily seen that the year-specific dummy for $\mathrm{CHN}$ is far below average for the years of 1980 and 1985; that is, -3.0196 for $C H N \_1980$ and -3.207 for CHN_1990 (see model 2) and relatively higher than the average of 1.0966 for $C H N \_1990$, CHN_1995, CHN_1998, and CHN_2000 (see model 3).

Table 2. Gravity Equation (Mainland China's Openness in Trade) Dep. Variable: Log of Bilateral VOT

\begin{tabular}{|c|c|c|c|c|c|c|}
\hline \multirow{2}{*}{$\frac{\text { Model }}{\text { Indep. Vars. }}$} & \multicolumn{2}{|c|}{1} & \multicolumn{2}{|c|}{2} & \multicolumn{2}{|c|}{3} \\
\hline & Coeff. & (Std. Err.) & Coeff. & (Std. Err.) & Coeff. & (Std. Err.) \\
\hline Yr1985 & -1.75271 & $(0.14372)$ & -1.78817 & $(0.14363)$ & -1.78937 & $(0.14358)$ \\
\hline Yr1990 & -1.76827 & $(0.12659)$ & -1.78241 & $(0.12654)$ & -1.78376 & $(0.12647)$ \\
\hline Yr1995 & -2.99299 & $(0.09604)$ & -3.03833 & $(0.09618)$ & -3.0377 & $(0.09627)$ \\
\hline Yr1998 & -2.77899 & $(0.0962)$ & -2.8244 & $(0.09634)$ & -2.82169 & $(0.09642)$ \\
\hline Yr2000 & -2.8315 & $(0.09667)$ & -2.8763 & $(0.0968)$ & -2.88377 & $(0.09687)$ \\
\hline LGDPij & 0.34705 & $(0.00695)$ & 0.34954 & $(0.00694)$ & 0.34962 & $(0.00694)$ \\
\hline LGNPPCij & 0.17625 & $(0.01845)$ & 0.17008 & $(0.01844)$ & 0.16991 & $(0.01844)$ \\
\hline LDIST & -1.15192 & $(0.01493)$ & -1.15024 & $(0.01491)$ & -1.15018 & $(0.01491)$ \\
\hline ADJ & 0.5132 & $(0.16039)$ & 0.51292 & $(0.16017)$ & 0.51293 & $(0.16017)$ \\
\hline LPPP_1980 & 3.12607 & $(0.07342)$ & 3.12291 & $(0.07332)$ & 3.12276 & $(0.07332)$ \\
\hline LPPP_1985 & 1.5235 & $(0.07762)$ & 1.49072 & $(0.07771)$ & 1.49219 & $(0.07759)$ \\
\hline LPPP_1990 & 1.43119 & $(0.06478)$ & 1.46835 & $(0.06518)$ & 1.4684 & $(0.06518)$ \\
\hline $\mathrm{CHN}$ & 3.2944 & $(0.16531)$ & 4.20986 & $(0.22874)$ & 1.09662 & $(0.28115)$ \\
\hline CHN_1980 & & & -3.01964 & $(0.45187)$ & & \\
\hline CHN_1985 & & & -3.20651 & $(0.45285)$ & & \\
\hline CHN_1990 & & & $0.68317^{\mathrm{a}}$ & $(0.45643)$ & 3.79602 & $(0.48388)$ \\
\hline CHN_1995 & & & & & 3.0049 & $(0.47946)$ \\
\hline CHN_1998 & & & & & 2.89167 & $(0.47952)$ \\
\hline CHN_2000 & & & & & 3.44201 & $(0.47955)$ \\
\hline $\mathrm{CnT}$ & -8.23992 & $(2.01095)$ & -8.24228 & $(2.00826)$ & -8.24237 & $(2.00826)$ \\
\hline CHT & 3.91905 & $(1.16456)$ & 3.92599 & (1.16301) & 3.92606 & (1.16301) \\
\hline ASEAN & 4.3675 & $(0.52164)$ & 4.36718 & $(0.52095)$ & 4.36717 & $(0.52095)$ \\
\hline NAFTA & 5.86276 & $(1.16515)$ & 5.87034 & (1.16359) & 5.87009 & (1.16359) \\
\hline EU & 2.90689 & $(0.23857)$ & 2.91496 & $(0.23826)$ & 2.91569 & $(0.23827)$ \\
\hline Obs. & 34561 & & 34561 & & 34561 & \\
\hline Adj. $\mathrm{R}^{2}$ & 0.7754 & & 0.7760 & & 0.7760 & \\
\hline
\end{tabular}

Note: All numbers without superscript 'a' are significant at $5 \%$ or $10 \%$ level. 


\section{Chinese Circle}

We now turn to examine whether there is a trading bloc made of a Chinese circle, including Taiwan, Hong Kong, and mainland China. For this purpose, extending from the benchmark model, two regional dummies of $C n T$ (mainland China and Taiwan) and CHT (mainland China, Hong Kong, and Taiwan) will be explored in more detail. The related year-specific dummies will be included into the regression under a different combination, as reported in Table 3 (regarding $C n T)$ and 4 (regarding $C H T$ ).

\section{(1) Mainland China and Taiwan}

It is believed that the trade between Taiwan and mainland China has been far below the normal level before the early 1980s, when mainland China's 'open' policy was in its infant stage, and for the Taiwan side capital flows were still under rigid regulation and direct trade with mainland China was still prohibited. To seek plausible evidence from the gravity model, various models are designed. Table 3 reports the regression results of several models with different combinations of $C n T$, CnT_1980, CnT_1985, and CnT_P1987 (referring to the CnT dummy of years after 1987, or mathematically $C n T *(Y r 1990+Y r 1995+Y r 1998+Y r 2000))$.

In Table 3, Model 1 has a significantly negative coefficient of -6.736 for the region dummy $C n T$, indicating that trade across the Strait has been far below normal in the past two decades. In addition, the trade flow was suppressed more in the early 1980s than in the 1990s, as shown in Models 2 and 3. Model 2 shows that for the years 1980 and 1985, the estimated CnT_1980 and CnT_1985 coefficients are respectively -16.39 and -15.11 , far below zero as compared with other years of 1.486 (the estimated coefficient for $C n T$, which is not significant). Both Models 3 and 4 consistently reveal the same pattern; that is, an extremely low level of trade across the Strait in the 1980s.

(2) Mainland China, Hong Kong, and Taiwan as a Bloc

In Table 3, despite the extremely low level of trade across the Strait (negative coefficient of $C n T$ ), the trade within the Chinese circle as a whole is shown to be far above the normal level. ${ }^{20}$ This empirically result, to some extent, supports the

\footnotetext{
${ }^{20}$ For the first 3 models in Table3, we can directly find a significantly positive coefficient of the dummy CHT. In model 4, however, the 'net' coefficient for the Chinese circle is the sum of the coefficient of CHT and the coefficient of EA5, for the region EA5 contains CHT.
} 
Table 3. Gravity Equation (Taiwan and Mainland China)

Dep. Variable: Log of Bilateral VOT

\begin{tabular}{|c|c|c|c|c|c|}
\hline Model & 1 & 2 & & 3 & 4 \\
\hline Indep.Vars. & Coeff. (Std. Err.) & Coeff. (Std. Err.) & Coeff. & (Std. Err.) & Coeff. (Std. Err.) \\
\hline Yr1985 & $-1.82545(0.1445)$ & $-1.82379(0.14447)$ & -1.8234 & (0.14446) & $-1.82308(0.14437)$ \\
\hline Yr1990 & $-1.81406(0.12729)$ & $-1.81596(0.12726)$ & -1.8158 & $(0.12726)$ & $-1.81452(0.12718)$ \\
\hline Yr1995 & $-2.98055(0.09659)$ & $-2.98334(0.09657)$ & -2.98319 & $(0.09656)$ & $-2.97844(0.0965)$ \\
\hline Yr1998 & $-2.76528(0.09675)$ & $-2.76807(0.09$ & -2.76792 & $(0.0$ & $-2.76329(0.09666)$ \\
\hline Yr2000 & $-2.81014(0.09721)$ & $-2.81287(0.0$ & -2.81272 & $(0.0$ & $-2.80819(0.09713)$ \\
\hline LGDPij & $0.37494(0.00684)$ & $0.37515(0.00684)$ & 0.37515 & $(0.00684)$ & $0.37311(0.00684)$ \\
\hline LGNPPCij & $0.10092(0.01816)$ & $0.10034(0.01816)$ & 0.10034 & $(0.01816)$ & $0.10265(0.01815)$ \\
\hline LDIST & $-1.15304(0.01502)$ & $-1.15287(0.0$ & -1.15287 & $(0.0$ & $-1.14702(0.01503)$ \\
\hline ADJ & $0.5077(0.16131)$ & $0.50773(0.16126)$ & 0.50772 & $(0$. & $0.52625(0.16119)$ \\
\hline LPPP_1980 & $3.17484(0.0738)$ & $3.17577(0.07378)$ & 3.17572 & $(0.07378)$ & $3.17146(0.07373)$ \\
\hline LPPP_1985 & $1.50044(0.07806)$ & $1.50208(0.07804)$ & 1.50217 & $(0.07804)$ & 1.4984 \\
\hline LPPP_1990 & $1.40106(0.06514)$ & $1.40193(0.06512)$ & 1.40193 & $(0.06512)$ & $1.39908(0.06508)$ \\
\hline $\mathrm{CnT}$ & $-6.73554(2.02102)$ & $-1.48615^{\mathrm{a}}(2.33241)$ & -17.236 & $(3.08474)$ & $-17.2147(3.08286)$ \\
\hline CnT_1980 & & $-16.3875(4.51354)$ & & & \\
\hline CnT_1985 & & $-15.1135(4.51363)$ & & & \\
\hline CnT_P1987 & & & 15.750 & $2(3$ & $743(3$ \\
\hline CHT & $5.48513(1.16855)$ & $5.48514(1.16824)$ & 5.48514 & $(1.1$ & $1.39022^{\mathrm{a}}(1.32299)$ \\
\hline EA5 & & & & & $4.10845(0.62434)$ \\
\hline ASEAN & $4.24054(0.52459)$ & $4.24062(0.52445)$ & 4.24062 & $(0.52444)$ & $4.25718(0.52413)$ \\
\hline NAFTA & 5.79067 & 5.79087 (1.17149) & 5.79088 & (1.17147) & $5.80014(1.17076)$ \\
\hline EU & $2.90424(0.23993)$ & 2.90499 (0.23987) & 2.90499 & $(0.23987)$ & $2.92579(0.23974)$ \\
\hline Obs. & 34561 & 34561 & 34561 & & 34561 \\
\hline Adj. $R^{2}$ & 0.7728 & 0.7729 & 0.7729 & & 0.7732 \\
\hline
\end{tabular}

Note: All numbers without superscript 'a' are significant at $5 \%$ or $10 \%$ level.

argument that there exists a significant trading bloc in the Chinese circle, and to some degree, Hong Kong does play the role of facilitating indirect trade for the officially-suppressed trade between Taiwan and mainland China.

More interesting features about the Chinese bloc can be further discovered from Table 4, in which in addition to the benchmark models some year-specific $C H T$ dummies are considered in the regression. Model 1 repeats the first benchmark model in Table 1, and as noted earlier we can find a significantly positive coefficient for $C H T$ (5.485), implying the existence of a trading bloc made of a Chinese circle in the past two decades. In fact, the fostering of this trading bloc did not become apparent until the 1990s, as shown in model 2. In the model, although the estimated coefficient for $C H T$ is 7.594, the coefficients for CHT_1980 and 
Table 4. Gravity Equation (Chinese Circle)

Dep. Variable: Log of Bilateral VOT

\begin{tabular}{|c|c|c|c|c|}
\hline Model & 1 & 2 & 3 & 4 \\
\hline Indep.Vars. & eff. (Std. Err.) & Coeff. (Std. I & Coeff. (Std. & oeff. (Std. I \\
\hline r1985 & $-1.82545(0.1445)$ & $-1.82482(0.14452)$ & $-1.82513(0.14441)$ & $-1.8245(0$ \\
\hline Yr1990 & $06(0.1$ & -1.8 & $-1.81278(0.1$ & $-1.81677(0$. \\
\hline r1995 & $55(0.0$ & $5(0.0$ & $-2.9758(0.0$ & $-2.98 \quad(0$. \\
\hline r1998 & -2.7 & -2 & -2 & -2 . \\
\hline Yr2000 & $-2.81014(0.09$ & $29(0.0$ & $61(0.0$ & $-2.80975(0$ \\
\hline GDPij & $0.37494(0.0$ & $0.37518(0.0$ & 0.37289 & 0.37313 \\
\hline PPCij & $92(0$. & $4(0$ & 0.1 & $65(0$ \\
\hline DIST & $04(0.0$ & -1 & -1 & $-1.147 \quad(0$ \\
\hline $\mathrm{DJ}$ & $0.5077 \quad(0.16131)$ & $0.50776(0.16129)$ & $0.52622(0.16$ & $0.52628(0$ \\
\hline PPP_1980 & $3.17484 \quad(0.0738)$ & $3.17634(0.07$ & $3.17058(0.0$ & $3.17208(0$. \\
\hline PPP_1 & $44(0.0$ & $9(0$. & $68(0.1$ & )1) \\
\hline PPP_1990 & $1.40106(0.0$ & $1.4014 \quad(0.0$ & $1.39821 \quad(0.0$ & $1.39855(0$ \\
\hline $\mathrm{EnT}$ & $-6.73554(2.02102)$ & $-6.73635(2.0$ & $-6.7156(2.0$ & $-6.71641(2$ \\
\hline $\mathrm{CHT}$ & $5.48513(1.16855)$ & $7.59415(1.50709)$ & $1.38984^{\mathrm{a}}(1.3$ & $3.49837(1$ \\
\hline CHT_1980 & & $-7.29614(2.6923$ & & $-7.29216(2$ \\
\hline CHT_1985 & & $-5.43408(2.69249)$ & & $-5.43213(2.69084)$ \\
\hline CHT_1990 & & $0.07559^{\mathrm{a}}(2.69222)$ & & $0.07544^{\mathrm{a}}(2.69057)$ \\
\hline EA5 & & & 4.10883 & 4.10835 \\
\hline ASEAN & $4.24054(0.52459)$ & $4.24059(0.5245$ & $4.2571 \quad(0.5$ & $4.25715(0$. \\
\hline NAFTA & 5.79067 (1.1718) & 5.7908 (1.17168) & $5.79993(1.17109)$ & $5.80005(1.17096)$ \\
\hline EU & $2.90424(0.23993)$ & $2.90503(0.23991)$ & $2.92504(0.23981)$ & $2.92583(0.23978)$ \\
\hline Obs. & 34561 & 34561 & 34561 & 34561 \\
\hline Adj. $R^{2}$ & 0.7728 & 0.7728 & 0.7731 & 0.7731 \\
\hline
\end{tabular}

Note: All numbers without superscript 'a' are significant at $5 \%$ or $10 \%$ level.

CHT_1985 are far below zero, i.e., -7.296 and -5.434 , respectively. As a result, the 'net' coefficient for CHT is about 0.298 in 1980 and 2.160 in 1985. Similar evidence for the fostering of a Chinese circle bloc can also be found from the result of Model 4, in which the regional dummy EA5 is included in the regression. Noting that the region $C H T$ is a subset of the region $E A 5$, we can also calculate the net coefficient of $C H T$ under various years; that is, $0.315(=3.498-7.292+4.108)$ for 1980, 2.175 for 1985, and 7.607 for the year 1990 and after. In sum, there exists $a$ trading bloc among the Chinese circle even in the early 1980s, and the bloc phenomenon has become more and more significant especially in the 1990s and after. 


\section{East asian five as a bloc}

To analyze the development of the East Asian bloc, various models are designed as reported in Table 5. Without considering EA5's year-specific dummy, Model 1

Table 5. Gravity Equation (East Asian Five)

Dep. Variable: Log of Bilateral VOT

\begin{tabular}{|c|c|c|c|c|}
\hline Model & 1 & 2 & 3 & 4 \\
\hline Indep. Vars. & Coeff. (Std. Err.) & Coeff. (Std. Err.) & Coeff. (Std. Err.) & Coeff. (Std. Err.) \\
\hline Yr1985 & $-1.78782(0.1435)$ & $-1.791 \quad(0.14364)$ & $-1.79233(0.1436)$ & $-1.79279(0.14354)$ \\
\hline Yr1990 & $-1.78864(0.12637)$ & $-1.79318(0.12647)$ & $-1.79488(0.12643)$ & $-1.79304(0.1264)$ \\
\hline Yr1995 & $-3.03936(0.096)$ & $-3.04499(0.09606)$ & $-3.04603(0.09602)$ & $-3.04301(0.09603)$ \\
\hline Yr1998 & $-2.82555(0.09616)$ & $-2.83058(0.09622)$ & $-2.83165(0.09618)$ & $-2.82921(0.09619)$ \\
\hline Yr2000 & $-2.87736(0.09662)$ & $-2.87639(0.09667)$ & $-2.88392(0.09664)$ & $-2.881(0.09665)$ \\
\hline LGDPij & $0.34856(0.00694)$ & $0.34893(0.00694)$ & $0.34892(0.00694)$ & $0.34869(0.00694)$ \\
\hline LGNPPCij & $0.17027(0.01843)$ & $0.17008(0.01843)$ & $0.16972(0.01843)$ & $0.17005(0.01843)$ \\
\hline LDIST & $-1.1456(0.01493)$ & $-1.14685(0.01$ & $-1.14587(0.01493)$ & $-1.14551(0.01493)$ \\
\hline ADJ & $0.52718(0.16011)$ & $0.5232(0.16013)$ & $0.52583(0.16011)$ & $0.52723(0.16011)$ \\
\hline LPPP_1980 & $3.12111(0.07328)$ & $3.12258 \quad(0.0733)$ & $3.12332(0.07328)$ & $3.12231(0.07328)$ \\
\hline LPPP_1985 & $1.49115(0.07755)$ & $1.49174(0.07759)$ & $1.49243(0.07758)$ & $1.4908(0.07755)$ \\
\hline LPPP_1990 & $1.45418(0.06472)$ & $1.45406(0.06474)$ & $1.45367(0.06473)$ & $1.45362(0.06472)$ \\
\hline $\mathrm{CHN}$ & $1.11644(0.28204)$ & $1.1437(0.28286)$ & $1.16498(0.28232)$ & $1.13515(0.28231)$ \\
\hline CHN_p1990 & $3.16208(0.34106)$ & 3.1447 (0.34249) & $3.09568(0.34208)$ & $3.1329(0.34161)$ \\
\hline CnT & $-16.5664(3.0712)$ & $-16.1671(3.15457)$ & $-14.999(3.13249)$ & $-15.874(3.10539)$ \\
\hline CnT_P1987 & $12.54958(3.48679)$ & 11.93311 (3.65062) & $10.19213(3.60635)$ & $11.51099(3.55432)$ \\
\hline CHT & $0.67154^{\mathrm{a}}(1.31468)$ & $1.56433^{\mathrm{a}}(1.28269)$ & $0.98503^{\mathrm{a}}(1.28336)$ & $0.67188^{\mathrm{a}}(1.31465)$ \\
\hline EA5 & $3.2945(0.62155)$ & & & $3.65075(0.66507)$ \\
\hline EA5_1980 & & $1.26726^{\mathrm{a}}(1.33719)$ & & $-2.13809^{\mathrm{a}}(1.42029)$ \\
\hline EA5_1985 & & 2.66884 (1.33749) & 2.71915 (1.3319) & \\
\hline EA5_1990 & & 3.13003 (1.31673) & 3.37391 (1.31894) & \\
\hline EA5_1995 & & 3.8047 (1.31644) & 4.04855 (1.31865) & \\
\hline EA5_1998 & & 3.47601 (1.31645) & 3.7199 (1.31867) & \\
\hline EA5_2000 & & & 4.00481 (1.31868) & \\
\hline ASEAN & $4.37709(0.52066)$ & $4.37392(0.52074)$ & $4.37588(0.52068)$ & $4.37697(0.52065)$ \\
\hline NAFTA & $5.87864(1.16294)$ & 5.87665 (1.16312) & 5.87797 (1.16298) & $5.87848(1.16292)$ \\
\hline EU & $2.93409(0.23814)$ & $2.92891(0.23817)$ & $2.9331 \quad(0.23814)$ & $2.93438(0.23813)$ \\
\hline Obs. & 34561 & 34561 & 34561 & 34561 \\
\hline Adj. $R^{2}$ & 0.7762 & 0.7761 & 0.7762 & 0.7762 \\
\hline
\end{tabular}

Note: All numbers without superscript 'a' are significant at $5 \%$ or $10 \%$ level. 
shows a significantly positive coefficient of $E A 5$, indicating somewhat the existence of an East Asian bloc during the last two decades. However, the fostering of this bloc seems not very apparent in the early 1980s. This is shown in Models 2, 3, and 4 , in which different combinations of year-specific region dummies of EA5 are included in the regression, and the dummies of EA5_1980 are insignificant. In addition, we can also find an increasing trend of the bloc phenomenon from 1980 to 1995 , as indicated by the coefficient of the corresponding year-specific dummy in Models 2 and 3. However, the bloc phenomenon seems to decline slightly after the financial crisis of 1997 , as indicated by the smaller coefficient of the EA5_1998, as compared with that of the EA5_1995. An increase in the estimated coefficient of EA5_2000 seems to indicate a re-fostering phenomenon in the East Asian Five.

In sum we may conclude that the East Asian bloc appeared in the late 1980 s and became more and more significant in the early 1990s. The bloc phenomenon weakened right after the Asian crisis in 1997 and re-fostered again a few years later.

\section{Concluding Remarks}

In this paper the gravity model has been applied to the years 1980, 1985, 1990, 1995, 1998, and 2000 to find empirical evidence of trading blocs in East Asia made up of mainland China, Taiwan, Hong Kong, Japan, and South Korea. The standard results for the gravity model, such as positive effects of GDP and GNP per capita, common border, and a negative effect of transport distance on the volume of bilateral trade, are confirmed. In addition, major findings regarding the plausible trading bloc in East Asia are as below:

(i) Although the open-door policy of mainland China can be dated back to 1979, the degree of openness for its trade is relatively lower for the years of 1980 and 1985 than for the years after the 1990s. In other words, mainland China's openness did not really become effective until the 1990s. (ii) The Chinese circle of Taiwan, Hong Kong, and mainland China as a trading bloc is empirically supported for the years 1980 and 1985 and has become more and more significant in the year of 1990 and after. (iii) Highly suppressed trade has occurred between mainland China and Taiwan especially for the periods before the 1987. (iv) The empiricallysupported co-existence of suppressed trade across the Strait and the above-normal trading bloc of the Chinese circle indirectly reflects the important role of Hong 
Kong as a trade agent in facilitating the trade flows among the region. (v) While mainland China's openness has become really effective after the 1990s, the East Asian bloc did not coincidentally become apparent until the late 1980s, and became more and more significant in the early 1990s. Although the East Asian's bloc phenomenon has weakened to some degree right after the Asian crisis of 1997, it fostered again a few years later.

Our findings also reflect the existence of market force in forming a factual trading blocs in East Asia. This findings implies a lot, especially in this period of growing regional trade agreement almost all over the world. That is, the conventional wisdom of FTA-induced effect, namely the trade creation between member countries, and trade diversion against non-member countries, have to be measured carefully. Trade creation may not be so big as normally expected, if the market mechanism in fact reveals little incentive for trade between the member countries. In fact, numerous different FTA documents and rules for different trade partners create a new form of transaction cost, so-called "spaghetti bowl effects", and hence will dampen the trade creation effect. Similarly, trade diversion against $3^{\text {rd }}$ country may not be so serious, if the direction of market force is "right" such that implicit gains from trading with some non-member countries are high.

\section{Acknowledgments}

The author thanks financial support from National Science Council (NSC 912415-H001030).

Received 17 March 2007, Accepted 27 November 2007

\section{References}

Anderson, J.E. (1979), “A Theoretical Foundation for the Gravity Equation”, American Economic Review, 69, pp.106-116.

Bergstrand, J.H. (1985), "The Gravity Equation in International Trade: Some Microeconomic Foundations and Empirical Evidence," Review of Economics and Statistics, 67, pp. 474-481.

Bonturi, M. and K. Fukasaku (1993), "Globalization and Intra-Firm Trade: An Empirical Note," OECD Economic Studies, Spring 1993, pp. 145-159.

Capie, D. (2004), "Rival Regions? East Asian Regionalism and Its Challenges to the AsiaPacific," in The Asia-Pacific: A Region in Transition, ed. Jim Rolfe. Honolulu, HI: 
Asia-Pacific Center for Security Studies, 149-165.

Chow, P., M. Kellman and Y. Shachmurove (1999), "A Test of the Linder Hypothesis In Pacific NIC trade 1965-1990," Applied Economics, 31, 175-182.

Deardorff, A.V. (1984), "Testing Trade Theories and Predicting Trade Flows," Handbook of International Economics, Vol. I, Amsterdam: 1984, pp.456-517.

Eichengreen, B. and D. A. Irwin (1995), "Trade Blocs, Currency Blocs and the Reorientation of Trade in the 1930s," Journal of International Economics, Vol. 38, pp.1-24.

Eichengreen, B. and D.A. Irwin (1996), "The Role of History in Bilateral Trade Flows," NBER Working Paper No.5565.

Feenstra, R. C., Markusen, J. A. and A K. Rose (2001), "Using the Gravity Equation to Differentiate Among Alternative Theories of Trade," Canadian Journal of Economics, 34(2): 430-47.

Frankel, J. (1992), "Is Japan Creating a Yen Bloc in East Asia and the Pacific?," the NBER conference on Japan and the U.S. in Pacific Area.

Frankel, Jeffrey A. and Shang-Jin Wei (1995), "The New Regionalism and Asia: Impact and Options," Working paper PB 95-10.

Frankel, J.A., Stein, E., Wei, S. J., (1995), "Trading blocs and the Americas: The Natural, the Unnatural, and the Super-natural," Journal of Development Economics, 47(1), pp. 61-95.

Frankel, J.A., Stein, E., Wei, S. J., (1996), "Regional Trading Arrangements: Natural or Supernatural," American Economic Review, 86(2), pp. 52-56.

Grant, R.J., M.C. Papadakis and J.D. Richardson (1993), "Global Trade Flows: Old Structures, New Issues, Empirical Evidence," Pacific Dynamism and the International Economic System, 1: 17-63.

Lee, J. W. and I. Park (2005), "Free Trade Areas in East Asia: Discriminatory or Nondiscriminatory?" World Economy, 28, pp. 21-48.

Linnemann, H. (1996), “An Econometric Analysis of International Trade Flows,” NorthHolland: Amsterdam.

Piazolo, D. (1997), "Trade Integration between Eastern and Western Europe: Policies Follow Market," Journal of Economic Integration, 12(3), pp.259-297.

Rauch, J. E. (1999), "Networks versus Markets in International Trade," Journal of Interna-tional Economics, 48, pp. 7-35.

Tinbergen, J. (1962), Shaping the World Economy: Suggestions for an International Economic Policy, New York. 


\title{
Appendix 1. List of Variables and Definitions
}

\author{
Variables \\ Descriptions
}

$L V O T_{i j}=\log \left(V O T_{i j}\right), \log$ of the volume of trade between country $i$ and $j$. If $V O T_{i j}=0$, then $L V O T_{i j}=\log$

(1).

Yr1985 Year dummy referring to the observation for year 1985, which takes a value one if the

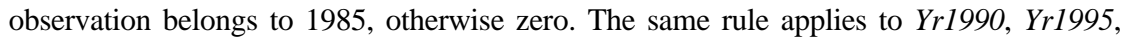
Yr1998, and Yr2000. (Note that the dummy Yr1980 is excluded to avoid singularity during the regression.)

$\operatorname{Lgdp_{ij}}=\log \left(G D P_{i}^{*} G D P_{j}\right)$

$\operatorname{Lgnppc}_{i j}=\log \left(G N P P C_{i} * G N P P C_{j}\right)$.

$L D I S T=\log (D I S T), \log$ of distance between trade partners.

$A D J_{i j} \quad$ Dummy of common border, equal to one if country $i$ and $j$ have a common border, otherwise zero.

ComLng $_{i j} \quad$ Dummy of common language, equal to one if country $i$ and $j$ have a common language, otherwise zero.

LPPP_1980 defined as the log of real exchange rate for year 1980. The same rule applies to LPPP_1985 and $L P P P \_1990$.

CHNij Openness dummy of mainland China, equal to one, if either the export side or the import side is mainland China, otherwise zero.

CHN_1980=CHN*(Yr1980); Year-specific dummy for the dummy $C H N$, equal to one if country $i$ or $j$ is mainland China and the observation is of 1980 , otherwise zero. The same system applies to other yearspecific $\mathrm{CHN}$ dummies, that is,

CHN_1985 =CHN*(Yr1985); CHN_1990 $=C H N^{*}(\operatorname{Yr} 1990)$;

CHN_1995=CHN*(Yr1995); CHN_1998=CHN*(Yr1998);

CHN_2000=CHN *(Yr2000);

$C n T_{i j} \quad$ Region dummy for the region of mainland China and Taiwan, which takes a value one if the observation is about trade between Taiwan and mainland China (i.e., if both country $i$ and $j$ represents Taiwan or mainland China), otherwise zero.

CnT_1980 =CnT * Yr1980, it is value one if the observation is of 1980 and about the bilateral trade between mainland China and Taiwan, otherwise zero. (The same system applies to CnT_1985,CnT_1990,CnT_1995,CnT_1998 and CnT_2000.

CnT_P1990 $=C n T *(Y r 1990+Y r 1995+Y r 1998+Y r 2000)$

CHT Region dummy for the Chinese circle, referring to the region group of mainland China, Hong Kong, and Taiwan, equals to one if both countries $i$ and $j$ are of the Chinese circle, otherwise zero.

CHT_1980=CHT * Yr1980; $C H T \_1985=C H T *(Y r 1985) ;$

CHT_1990 $=$ CHT $*(Y r 1990)$;

EA5 Region dummy for the region of the five East Asian economies: mainland China and Taiwan, Hong Kong, South Korea, and Japan, which takes a value of one if both countries $i$ and $j$ are of the five economies, otherwise zero.

$E A 5 \_1980=E A 5 *(Y r 1980) ; E A 5 \_1985=E A 5 *(Y r 1985) ; E A 5 \_1990=E A 5 *(Y r 1990) ;$

$E A 5 \_1995=E A 5 *(\operatorname{Yr} 1995) ; E A 5 \_1998=E A 5 *(Y r 1998) ; E A 5 \_2000=E A 5 *(Y r 2000)$;

ASEAN Region dummy for five member countries of ASEAN: Singapore, Malaysia, Thailand, Philippine and Indonesia.

NAFTA Region dummy for the North American Free Trade Area, United States, and Canada for years before 1994, and United States, Canada, and Mexico for Years 1995 and after.

EU Regional dummy for European Union. For year 1980, the members are Belgium, Denmark, France, Germany, Ireland, Italy, Luxembourg, Netherlands, and United Kingdom. In 1981 Greece joined the groups; in 1986 two more members entered, Portugal and Spain; in 1995 Austria, Finland, Sweden became three new members. 


\section{Appendix 2. The 108 Countries Included in the Sample}

Algeria, Antigua-Barbuda, Argentina, Australia, Austria, Bahamas, Bangladesh, Barbados, Belgium, Belize, Benin, Bolivia, Brazil, Burkina Faso, Burundi, Cameroon, Canada, Chad, Chile, China, Colombia, Comoros, Congo, Rep. Costa Rica, Cote d'Ivoire, Cyprus, Denmark, Dominican Republic, Ecuador, Egypt, El Salvador, Fiji, Finland, France, Gabon, Gambia, The Germany, Ghana, Greece, Guatemala, Guinea-Bissau, Guyana, Haiti, Honduras, Hong Kong, Hungary, Iceland, India, Indonesia, Iran, Islamic Rep., Ireland, Israel, Italy, Jamaica, Japan, Jordan, Kenya, Korea Rep., Kuwait, Madagascar, Malawi, Malaysia, Mali, Malta, Mauritania, Mauritius, Mexico, Morocco, Mozambique, Nepal, Netherlands, New Caledonia, New Zealand, Nicaragua, Niger, Nigeria, Norway, Pakistan, Panama, Papua New Guinea, Paraguay, Peru, Philippines, Portugal, Romania, Rwanda, Saudi Arabia, Senegal, Sierra, Leone, Singapore, South Africa, Spain, Sri Lanka, Sudan, Suriname, Sweden, Switzerland, Taiwan, Thailand, Togo, Tunisia, Turkey, United Kingdom United States, Uruguay, Venezuela, RB, Zambia Zimbabwe. 